\title{
PINTURA
}

\section{O OLHAR MÁGICO DE ESCHER: EXPOSIÇÃO MOSTRA RELAÇÃO ÍNTIMA ENTRE CIÊNCIA E ARTE}

Metamorfoses, construções impossíveis, flutuar no nada, explorações do infinito, imagens se desmanchando no espelho. As obras de Mauritius Cornelius Escher são um verdadeiro desafio à lógica que intrigam e seduzem um público que vai desde crianças até renomados matemáticos e críticos de arte. Por conta de tal leque variado, a exposição $O$ mundo mágico de Escher, a mais completa já realizada no Brasil dedicada ao artista gráfico holandês, foi um sucesso em sua temporada no Rio de Janeiro, entre janeiro e março, chegando a São Paulo em maio. A primeira parada foi Brasília, para comemorar os 10 anos de existência do Centro Cultural Banco do Brasil (CCBB), onde recebeu cerca de 250 mil pessoas. No Rio de Janeiro, só nas três primeiras semanas, mais de 150 mil visitantes.

MAGIA, ENIGMA E INTERAÇÃO O acervo de 95 obras, entre gravuras originais, desenhos e fac-símiles, compõe a exposição, incluindo todos os trabalhos mais conhecidos - e enigmáticos - do artista, como Dia e Noite (1938) e Metamorphosis II (1940). Para explorar esse "mundo mágico" do artista, a mostra brinca com os sentidos e a percepção dos visitantes, recriando alguns dos efeitos utilizados por Escher. Ao total, são seis

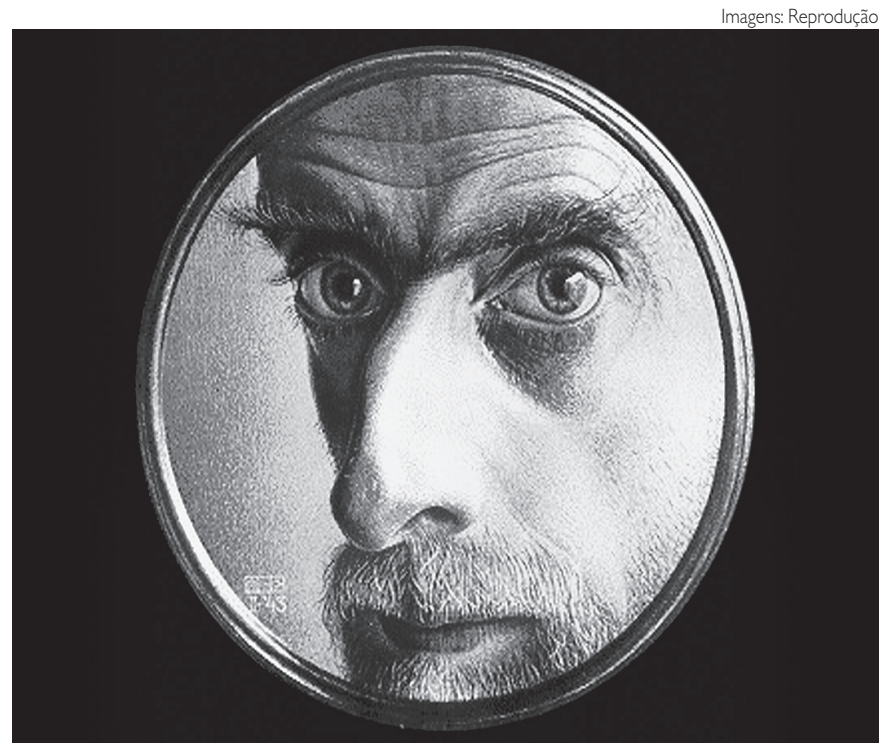

Artista gráfico holandês, Maurits Cornelis Escher (1898-1972) ambientes interativos em que o público pode, literalmente, experimentar as obras. Esses ambientes estão reunidos na galeria Sala dos Enigmas. "Quero que as pessoas parem para pensar o que estão vendo. Questionem o conceito, voltem para trás para rever a obra, depois de terem participado das instalações", explica o curador Pieter Tjabbes. Cada instalação discute um efeito que pode ser observado em suas obras, como o de uma imagem "plotada" no chão que se completa em um espelho curvado, numa divertida mistura das três dimensões; ou então em uma brincadeira em que o visitante pode mexer para modificar os efeitos da obra, como num programa touchscreen; ou ainda um quebra-cabeça gigante, com imagens geométricas ou figurativas que se unem umas às outras para criar gravuras que remetem ao infinito.

Também foi montada uma casa com duas janelas em tamanhos diferentes, com teto e piso inclinados. Nessa casa, dependendo da posição, a pessoa parecerá um gigante ou um pigmeu. $\mathrm{O}$ visitante ainda poderá passear por um labirinto, observar um buraco sem fundo ou admirar cenários que viram de cabeça para baixo dependendo de onde partir o olhar. "As perspectivas arquitetônicas de Escher se misturam e causam um efeito de combinaçôes isométricas e fazem o olhar não conseguir se fixar num só lugar. $\mathrm{O}$ olhar passeia sem descanso pela obra”, declara a historiadora da arte Sandra Hitner. A ideia das instalações é traduzir os princípios usados por Escher para a realidade. Para isso, Tjabbes reuniu um time de especialistas: arquitetos, técnicos em iluminação, especialistas em espelhos e vídeos tridimensionais que, juntos, criaram os atrativos extras da mostra.

Os originais trazidos da Holanda Sala Multiuso. Nesse mesmo espaço acontece a exibição permanente de um documentário sobre Escher, de uma hora de duração. Além de outros vídeos de animação inspiraestão reunidos em outra galeria, a 

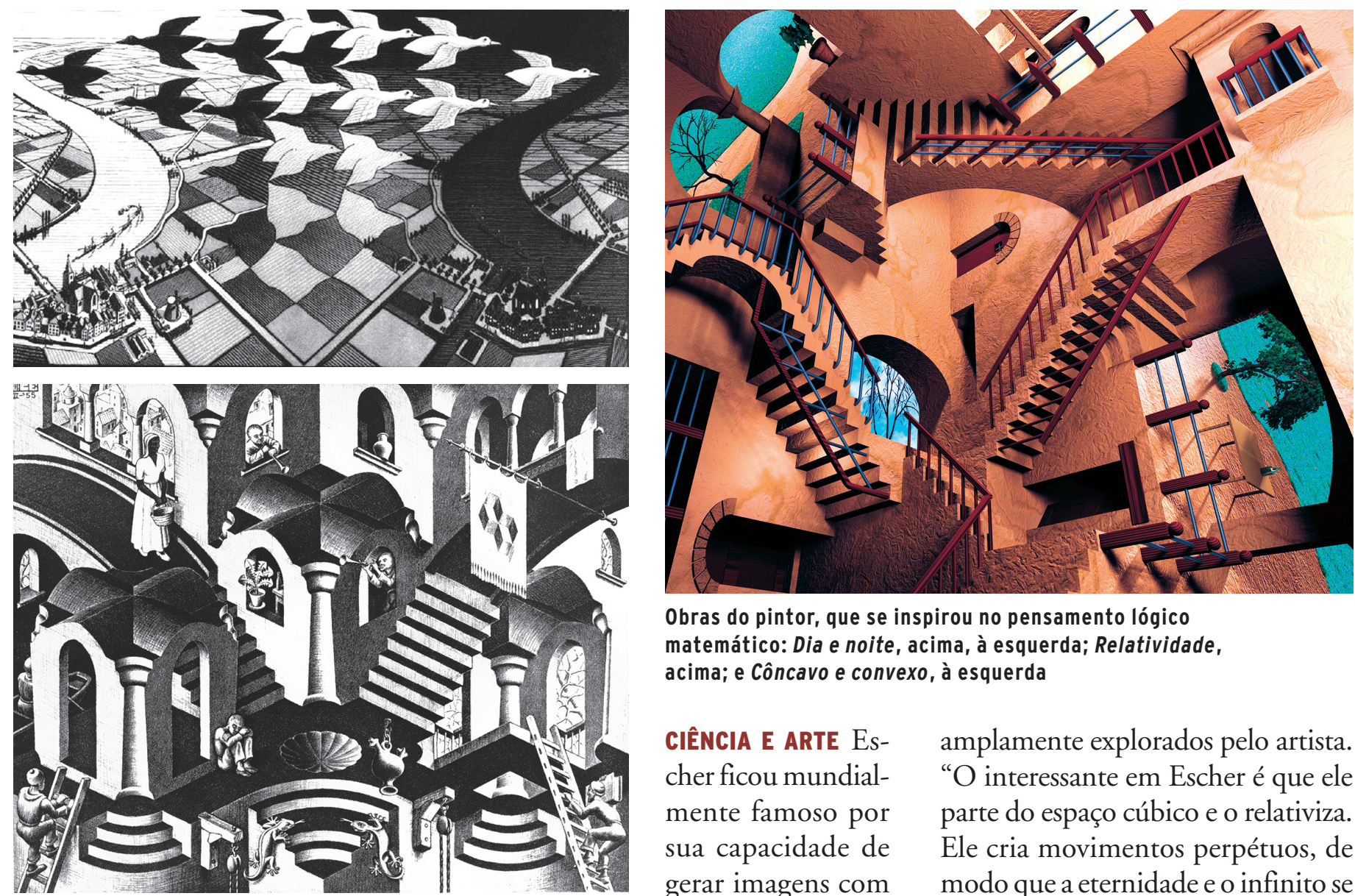

Obras do pintor, que se inspirou no pensamento lógico matemático: Dia e noite, acima, à esquerda; Relatividade, acima; e Côncavo e convexo, à esquerda

CIÊNCIA E ARTE EScher ficou mundialmente famoso por sua capacidade de gerar imagens com impressionantes dos em suas obras, apresentados em sete monitores espalhados pelo ambiente. Para completar, os visitantes poderão assistir um filme em $3 \mathrm{D}$ de nove minutos que possibilitará um divertido passeio por dentro das obras do artista. A fundação que cuida do acervo de Escher comprou os direitos autorais para reproduzir no museu holandês algumas das instalações criadas pela exibição brasileira. "Fizemos uma mistura total de obras originais, ampliações e instalações interativas, para que o público tenha surpresas a cada momento. Acho que assim se consegue entender melhor a obra e também se mantém a atenção ligada o tempo todo", afirma Tjabbes. efeitos de ilusão de ótica, sem deixar de lado as regras geométricas do desenho e da perspectiva e com uma notável qualidade técnica e estética. Considerado um artista único, foi quem melhor conseguiu reunir arte e ciência para transformar o pensamento matemático moderno em imagens. Atualmente, suas obras estão em alta, pois serviram de inspiração para o filme Origem (Inception - 2010), dirigido por Christopher Nolan e protagonizado por Leonardo Di Caprio. No filme, construções inteiras se desmancham para criar outras novas, escadas sem fim levam ao mesmo lugar, jogos de espelho criam corredores infinitos, numa tradução cinematográfica dos conceitos amplamente explorados pelo artista. "O interessante em Escher é que ele parte do espaço cúbico e o relativiza. Ele cria movimentos perpétuos, de modo que a eternidade e o infinito se visualizem. Ele destrói o espaço pela impossibilidade de sua existência na possível concepção de sua realidade”, diz Angela Ancora da Luz, historiadora, crítica de arte e professora da Escola de Belas Artes da Universidade Federal do Rio de Janeiro (UFRJ). Fascinado por matemática e intrigado com as limitaçôes do olho humano, Escher passou a vida a investigar como transpor para as duas dimensões da folha de papel as perspectivas imperceptíveis à visão humana. $\mathrm{O}$ artista brincava com a tridimensionalidade do espaço e a bidimensionalidade do papel, em imagens distorcidas, e outras que jogam com a percepção enganosa do olhar. Esse processo invariavelmente levava a representaçôes distorcidas e enig- 
máticas. "Ele pensava a realidade como um conjunto de correlações, um emaranhado de núcleos interconexos que trocam permanentemente energia e informação. A subdivisão dos espaços, em algumas de suas obras, pode ser descrita ou explicada como se a descontinuidade pudesse ser reconduzida a uma continuidade que compreende, ao mesmo tempo, tanto a causa quanto os efeitos na gênese das formas. É como se dos conflitos formais, redundasse uma nova alternativa de perspectiva aeroespacial”, aponta Hitner.

Desprezado pela crítica da época por conta do caráter decorativo das gravuras, Escher ganhou a simpatia dos cientistas, especialmente dos matemáticos, antes mesmo de conquistar os críticos de arte. Em uma de suas frases mais conhecidas, ele brincava que tinha mais em comum com os matemáticos do que com os outros artistas. "O trabalho de Escher não está em nenhum dos movimentos das vanguardas históricas, por exemplo. Suas obras não podem ser classificadas ou nomeadas por uma ou outra corrente. O que se pode afirmar é que sua arte se caracteriza por uma afinidade construtiva. Trata-se de um artista figurativista, que busca recursos na matemática, pela divisão de planos, pelo uso de espirais, rotações, inversões de figuras, rebatimentos, espelhamentos, enfim, uma gama rica de critérios exatos para criar o insondável, o impossível, materializando o imaterial, sem fronteiras que separem dentro e fora, acima e abaixo, luz e opacidade, verdade e ficção", pontua Angela.

Chris Bueno

\section{CINEMA}

\section{O MUNDO DO TRABALHO RETRATADO NAS TELAS}

O trabalho sem fronteiras, que permita ao indivíduo usufruir da liberdade de ir e vir a locais geográficos onde a mão de obra seja bem paga e as condições de emprego e remuneração assim como de realização pessoal e profissional sejam mais atraentes, é o sonho contemporâneo. Infelizmente, esta não é a realidade que vivemos: fronteiras caem para produtos e serviços, o capital circula onde lhe é mais lucrativo e com melhores condiçôes de se multiplicar, mas a extensa massa de trabalhadores do planeta, sem especialização e sem postos qualificados, oscilam à mercê da decisão dos investidores. Essa é uma questão econômica e sociológica que, além de fomentar teses acadêmicas e artigos de especialistas, tem sido habilmente tratada por vários cineastas, não só nas obras de ficção - em clássicos como o espanhol Segunda-feira ao sol, o norte-americano Pão e rosas, o francês $O$ corte ou o indiano Sob a luz da América - mas, principalmente, nos documentários produzidos nas últimas décadas.

Mesmo o documentário não sendo, ainda, um gênero de apelo popular como grandes produçôes cinematográficas, diversos deles acabam por cumprir melhor o papel de de-

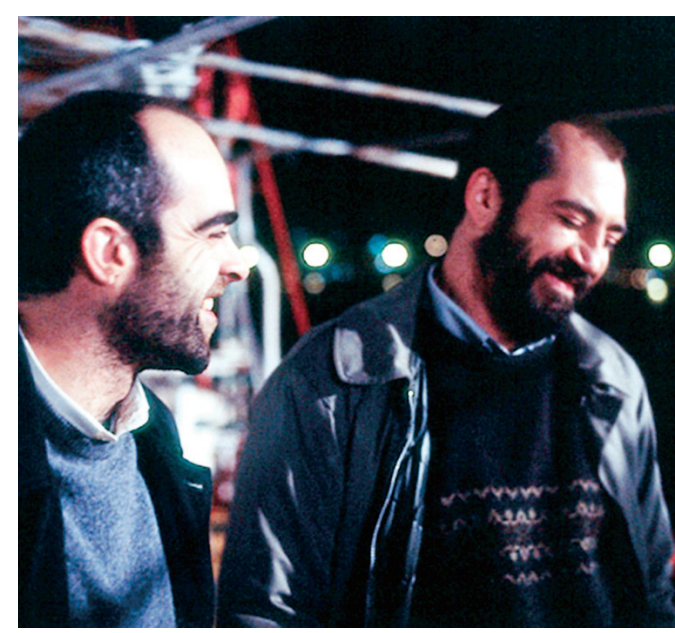

Cenas de filmes que retratam a perda da identidade com 0 desemprego, como a ficção Segunda-feira ao sol (acima), e e a precarização e exploração do trabalho na economia globalizada, caso do documentário China Blue

núncia do problema, em especial os que conseguem ser veiculados pelas TVs abertas ou pagas. Recentemente incluído na programação da TV Cultura, China Blue é um dos casos: retrata a realidade de operárias chinesas numa pequena fábrica têxtil de jeans, cuja produção globalizada as joga num mundo escravizado do trabalho a baixo custo para as grandes marcas internacionais. Embora trabalhadoras urbanas, sofrem exploração como nos modelos rurais mais arcaicos: refeições e moradia são deduzidos de seus salários que, no caso, não chegam a um dólar diário. China Blue mostra o cotidiano dessas fábricas do sudoeste da China, com adolescentes retiradas de suas aldeias para sobreviver em cruéis condições de trabalho. Feito sem a permissão das autoridades chinesas é exemplar ao retratar a realidade da produção nos países emergentes. 